\title{
Performance Analysis of PI and Fuzzy-Logic Controlled DSTATCOM for PQ Improvement
}

\author{
J. Ganesh Prasad Reddy ${ }^{1}$, Dr. K. Ramesh Reddy ${ }^{2}$ \\ ${ }^{1}$ Research Scholar, Department of EEE, JNTU Hyderabad, Hyderabad, Telangana, India \\ ${ }^{2}$ Principal, G. Narayanamma Institute of Technologyand Science for Women, Shaikpet, Hyderabad, Telangana, \\ India 1'jgpreddy@gmail.com
}

\begin{abstract}
Power quality is one area which concerns the electrical professionals today. Advances in power electronics usage in variable frequency drives, distributed generations and uninterrupted power supply destroy the quality of power in distribution system. Harmonics especially destroys the shape of the source current and reduces the distribution equipment's capacity. This paper presents a performance comparison of both Fuzzy-logic controller and PI controller based FACTS devices for power quality enhancement in power-distribution network. Five-Level DSTATCOM is employed for PQ enhancement. LSCPWM pattern of pulses excites the DSTATCOM while reference signals are obtained from IRP based theory. PI and fuzzy controller performance (in the process of generating reference currents) in enhancing the power quality reducing the harmonic current distortion in distribution system is analysed in this paper.
\end{abstract}

Key words: DSTATCOM, Fuzzy-Logic Controller, Multilevel Inverter, Instantaneous Power Controller, PI Controller, Power-Quality Improvement.

\section{INTRODUCTION}

Quality in power [1-3] is an important terminology for different sections of power network. Power supplier concentrates on the standards to supply good power and the consumer focuses to use the qualified power delivered by the supplier. Any issues related to quality in power influences efficiency and interrupt the continuity of supply [4]. A short duration issue in power quality corrupts the functioning of the system [5-6]. Presence of power adaption and power electronic devices pollutes the power system by inducing harmonics [7]. The induced harmonics overheats the windings, vibrates the motor, and results in low power factor.

Efficient harmonic reduction techniques are of important in view of costumer and the load devices [8]. Effectiveness of passive filters is questioned and recent trend is to use power electronic converter based DSTATCOM (distribution static compensator) to compensate harmonics.

The DSTATCOM consists of VSI; it is integrated at feeding or common-coupling point (PCC) of distribution system to generate in-phase harmonic sequences for compensating the harmonics coming from the non-linear loads result the source current as sinusoidal, balanced, fundamental nature [9]-[11]. The block-diagram of DSTATCOM connected in three-phase distribution system is depicted in Figure 1.
This paper confers the performance comparison of Fuzzy and PI controllers driven 5-level DSTATCOM for PQ enhancement in a three-phase distribution system. The proposed 5-level DSTATCOM topology is controlled by using LSCPWM switching pattern while reference current signals are received from IRP control theory.

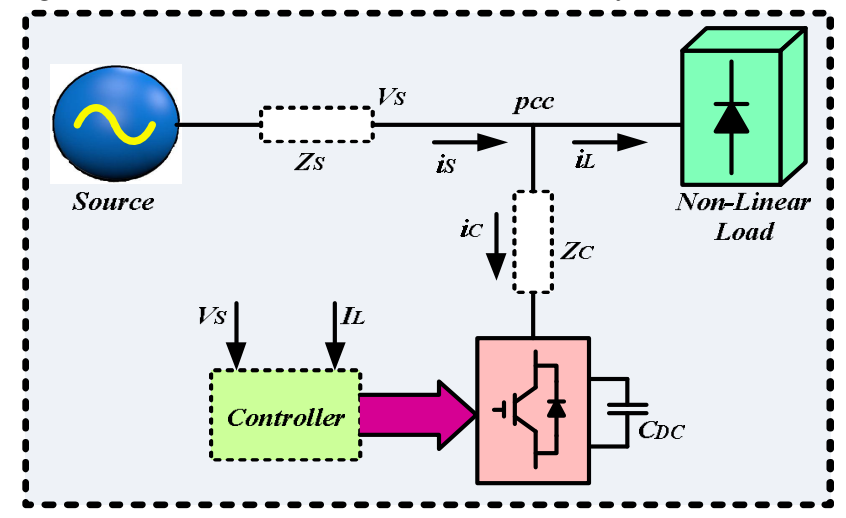

Figure 1: Block diagram of DSTATCOM in distribution system

The PI and fuzzy controller performance (in the process of generating reference currents) in enhancing the power quality reducing the harmonic distortion in source current is analyzed in this paper. The simulation results of proposed 5-level DSTATCOM topology are analyzed under both balanced and un-balanced non-linear loads by using Matlab/Simulink tool.

\section{PROPOSED MULTILEVEL DSTATCOM}

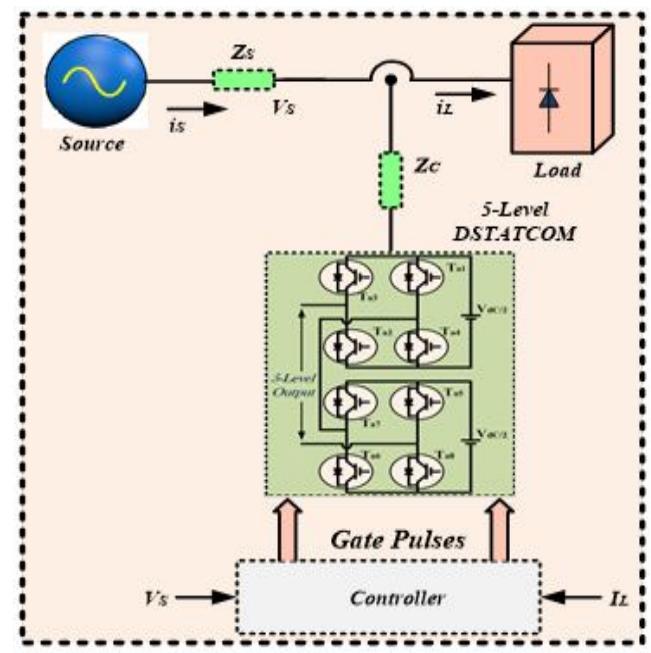

Figure 2: Multi-Level CHB structured DSTATCOM in power distribution system 
J. Ganesh Prasad Reddy et al., International Journal of Emerging Trends in Engineering Research, 8(9), September 2020, 5135 - 5142

Multi-level concept is trending these days and they are capable of meeting the load demand. Generating output voltage with less distortion and reduced stress across switch are the highlight features of multi-level inverters. Cascaded H-Bridge MLI structure is employed to give out leveled output from VSI of DSTATCOM, only one phase representation of CHB-MLI is shown. Medium range voltage level with high power requirements makes use of MLIs. The CHB-MLI consists of several H-Bridge modules which are connected as series or cascaded form to get high voltage levels. On phase module representation of $\mathrm{CHB}$ based multi-level DSTATCOM is depicted in Figure 2.

\section{PROPOSED FUZZY-LOGIC BASED IRP CONTROLLER}

Current harmonics in source currents generated from non-linear load are compensated using five-level DSTATCOM controlled by IRP algorithm. A transformation from three-coordinates to two-coordinate terminology of voltage and load current is the base step. Meanwhile, the DC-link power loss is measured by differential value of set and actual DC-Link voltages using PI / Fuzzy controllers. Fuzzy controller transforms the input data to fuzzier data and relates to rule base set (as in Table.1). Error signal is de-fuzzier and generates reference signal. Inverse transformation of reference signals generates gate pulses to inverter circuit.

Table.1 Fuzzy Rules

\begin{tabular}{|c|c|c|c|c|c|c|}
\hline & \multicolumn{6}{|c|}{ Error $(\mathrm{E})$} \\
\hline \multirow{6}{*}{$\begin{array}{c}\text { Change } \\
\text { in } \\
\text { Error } \\
(\Delta \mathrm{E})\end{array}$} & & $\mathrm{N}-\mathrm{B}$ & $\mathrm{N}-\mathrm{S}$ & Z-E & P-S & P-B \\
\hline & N-B & $\mathrm{N}-\mathrm{B}$ & $\mathrm{N}-\mathrm{B}$ & $\mathrm{N}-\mathrm{S}$ & $\mathrm{N}-\mathrm{S}$ & Z-E \\
\hline & $\mathrm{N}-\mathrm{S}$ & $\mathrm{N}-\mathrm{B}$ & $\mathrm{N}-\mathrm{S}$ & $\mathrm{N}-\mathrm{S}$ & Z-E & P-S \\
\hline & Z-E & $\mathrm{N}-\mathrm{S}$ & $\mathrm{N}-\mathrm{S}$ & Z-E & P-S & P-S \\
\hline & P-S & $\mathrm{N}-\mathrm{S}$ & Z-E & P-S & P-S & P-B \\
\hline & P-B & Z-E & P-S & P-S & P-B & P-B \\
\hline
\end{tabular}

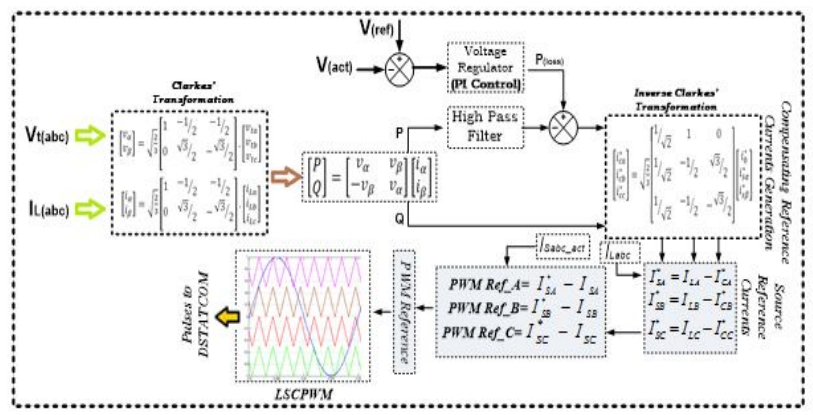

Figure 3: PI based IRP control for DSTATCOM

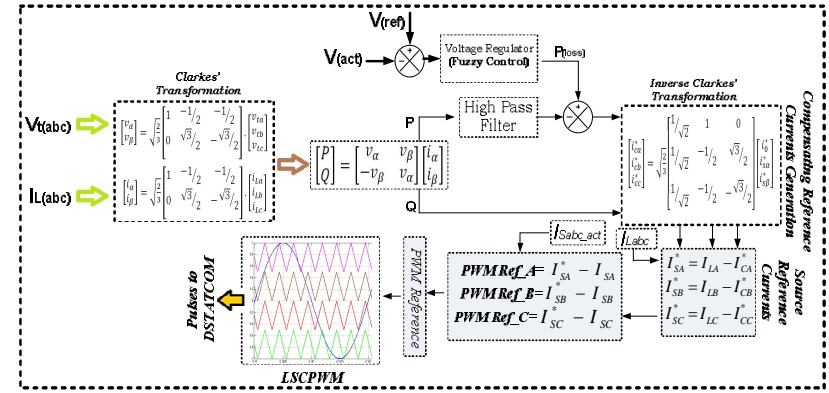

Figure 4: Fuzzy based IRP control for DSTATCOM

The proposed PI-IRP and Fuzzy-IRP control schemes produce the switching states to CHB-MLI drive DSTATCOM and the control circuits are clearly depicted in Figure. 3 and Figure.3. The over-all circuit representation of proposed 5-level CHB-MLI driven DSTATCOM topology is depicted in Figure.5.

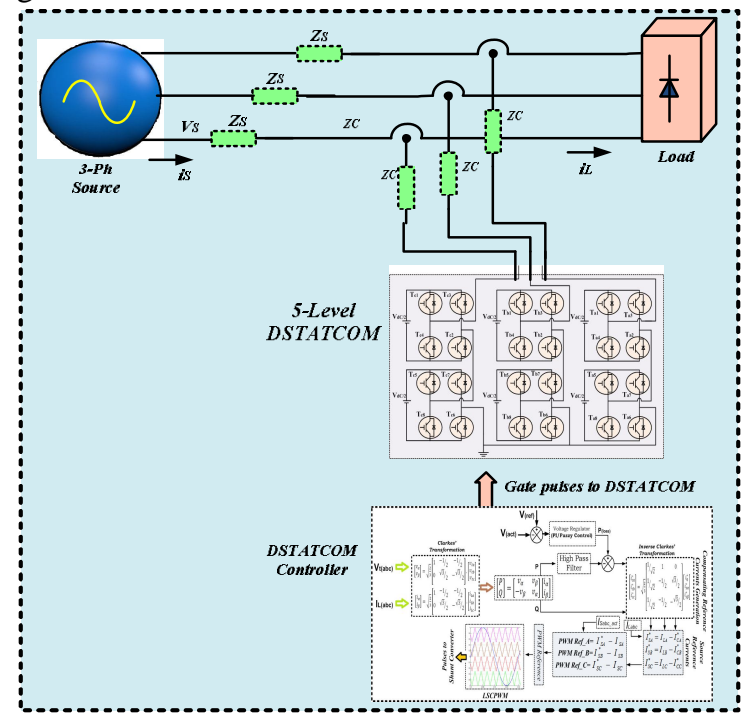

Figure 5: Overall circuit representation of PI/Fuzzy controlled DSTATCOM

\section{MATLAB/SIMULINK RESULTS}

The performance of proposed IRP-fuzzy-logic controlled Five-Level DSTATCOM topology is verified under both un-balanced and balanced non-linear loads by utilizing Matlab/Simulink tool. Table.2 shows the system specifications of proposed model.

Table.2 System Specifications

\begin{tabular}{|l|l|}
\hline \multicolumn{1}{|c|}{ Parameter } & \multicolumn{1}{c|}{ Value } \\
\hline Supply Voltage & $11 \mathrm{KV}, 50 \mathrm{~Hz}$ \\
\hline Line Impedance & $0.1 \mathrm{Ohms}, 0.9 \mathrm{mH}$ \\
\hline DC Link Capacitance & $1550 \mu \mathrm{F}$ \\
\hline Filter Impedance & $0.001 \mathrm{Ohms}, 0.9 \mathrm{mH}$ \\
\hline $\begin{array}{l}\text { Carrier signal } \\
\text { frequency }\end{array}$ & 3960 \\
\hline
\end{tabular}


J. Ganesh Prasad Reddy et al., International Journal of Emerging Trends in Engineering Research, 8(9), September 2020, 5135 - 5142

\subsection{Balanced Non-Linear load compensation with PI Controller}

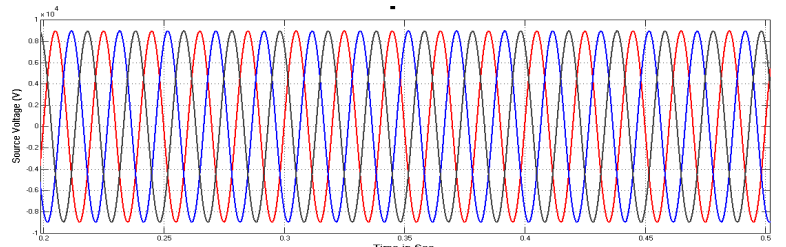

(a) Source Voltage

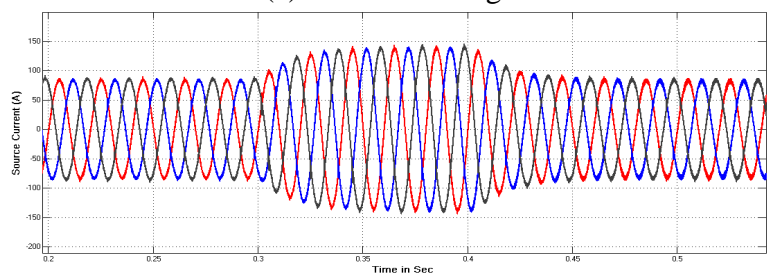

(b) Source current

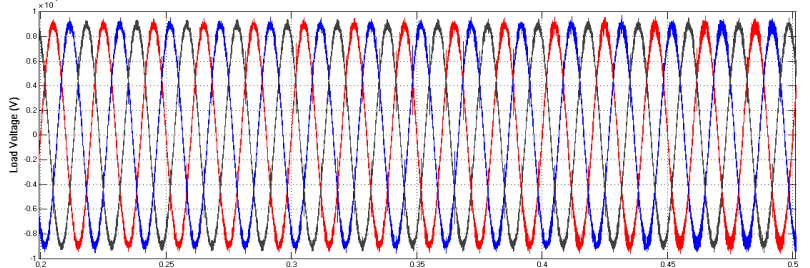

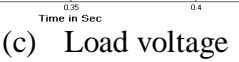

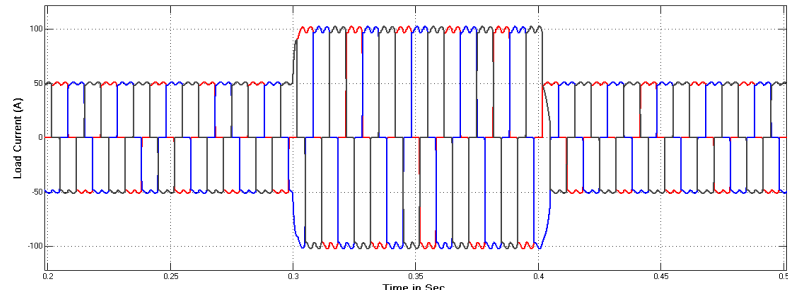

(d) . Load current

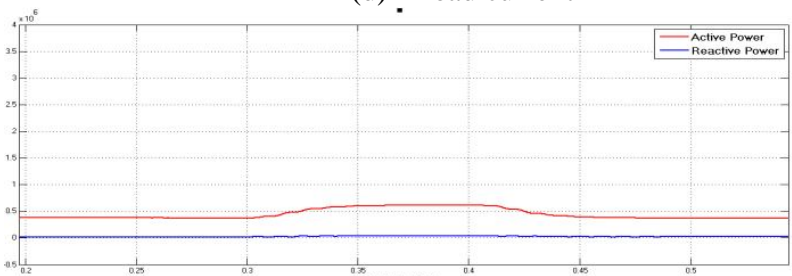

(e) Source Active and reactive powers

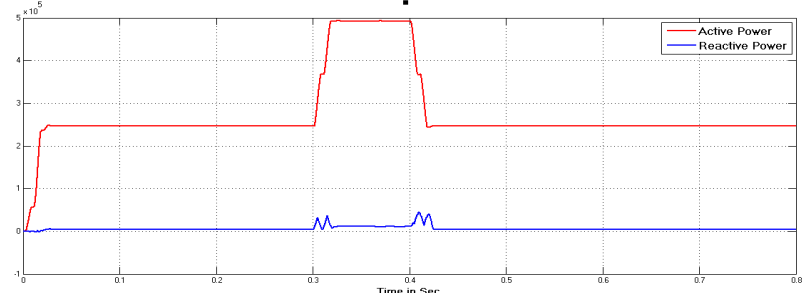

(f) Load active and reactive powers

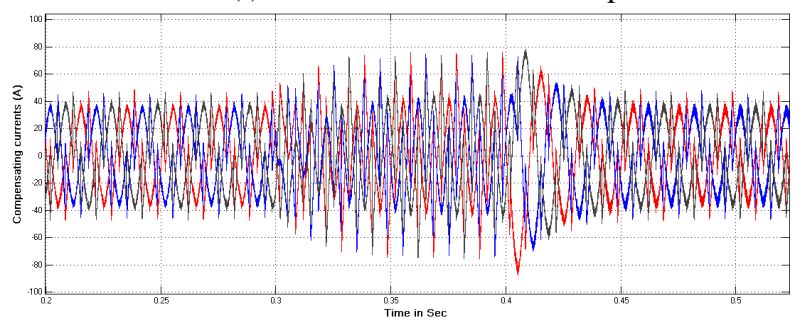

(g) Compensating currents from DSTATCOM

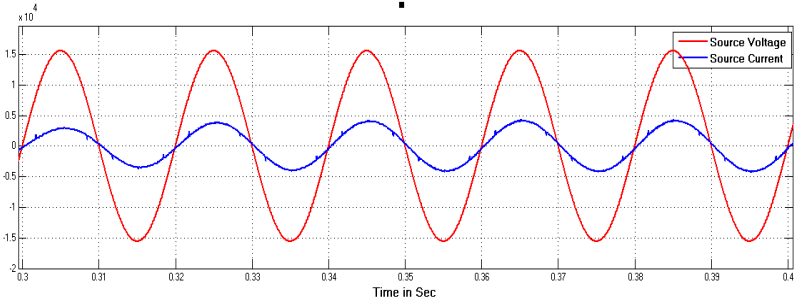

(h) source power factor

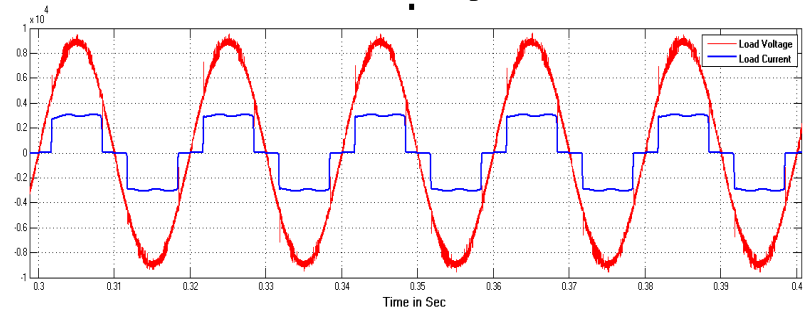

(i) Load power factor

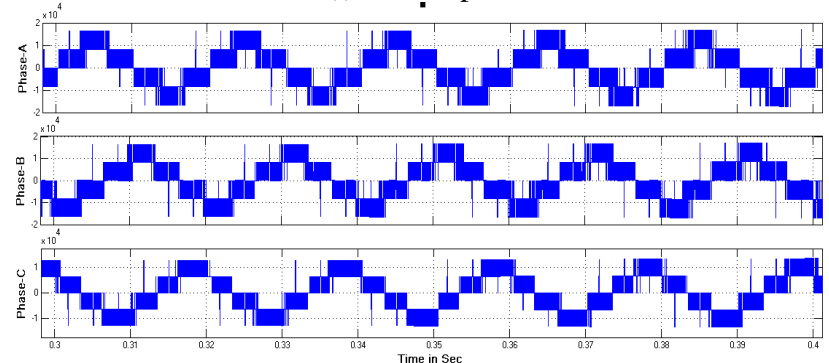

(j) 5-level output of multi-level DSTATCOM - Dignal to analyze selected signal $O$ Display FFT window
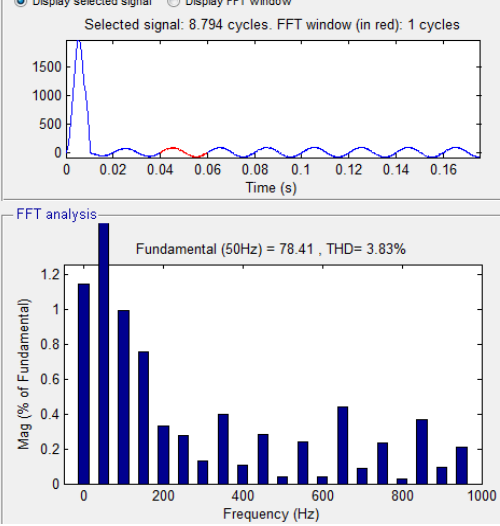

(k) THD in source current

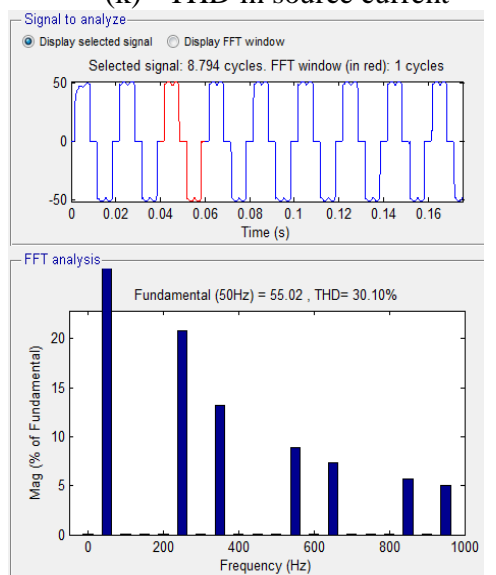

(l) THD in load current

Figure.6 Simulation Results of Balanced Non-Linear Load with PI Based IRP Controller 
J. Ganesh Prasad Reddy et al., International Journal of Emerging Trends in Engineering Research, 8(9), September 2020, 5135 - 5142

The simulation results of proposed 5-level CHB-MLI based DSTATCOM for PQ enhancement under non-linear balanced load by using traditional PI-IRP controller are clearly presented in Figure.6. In that, three-phase RMS $11 \mathrm{KV}$ is used as source voltage with a frequency of $50 \mathrm{~Hz}$. The source current is also maintained as sinusoidal because the 5-level CHB-MLI DSTATCOM topology is integrated at PCC of distribution system. Other than, the source current is always accordance with load current due to presence of non-linear loads. Suddenly the source current is increased with in a time period of $0.3 \mathrm{sec}$ to $0.4 \mathrm{sec}$ to achieve the load demand. The load voltage also maintained as sinusoidal and fundamental with a value of RMS $11 \mathrm{KV}$. Due to the non-linear load, the load current is highly harmonized components. The source side active power is also increased with respect to the increments in load while reactive power is maintained as zero. The 5-level CHB-MLI DSTATCOM injects the compensation current into PCC of distribution system to achieve three-phase distribution as balanced, sinusoidal, fundamental and linear nature by using in-phase compensation principle. Then the source current is in-phase with the voltage to represent the source side power-factor as unity. On other-hand, the load current is out of the phase with the load voltage to represent load side power-factor as non-unity condition. The 5-level CHB-MLI produces the stair-case voltage wave-shapes to represent the three-phase 5-level voltage. The harmonic profile of load current is $30.10 \%$ which is very high due to presence of balanced non-linear load and the source current is measured as $3.83 \%$ through FFT analysis, it is well within IEEE-519 standards.

\subsection{Balanced Non-Linear load compensation with Fuzzy Controller}

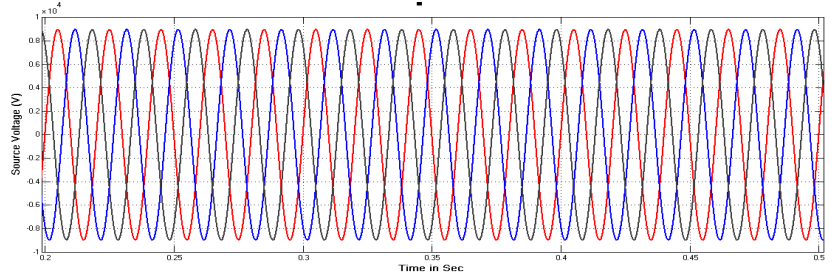

(a) Source Voltage

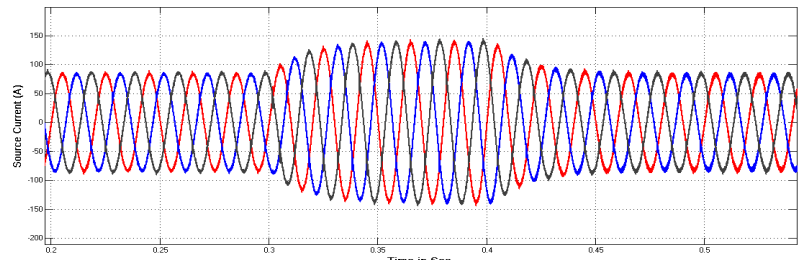

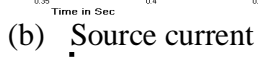

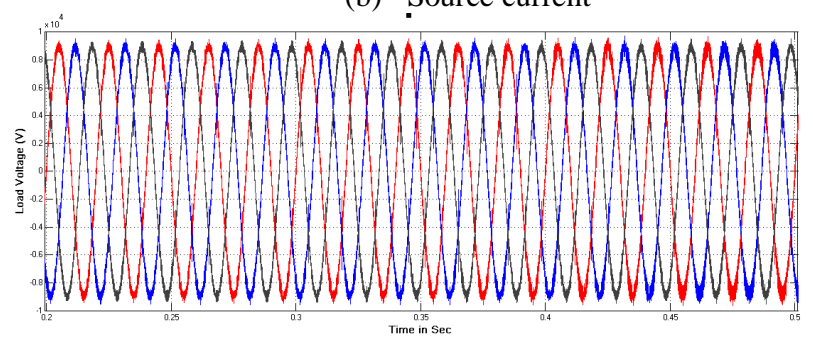

(c) Load voltage

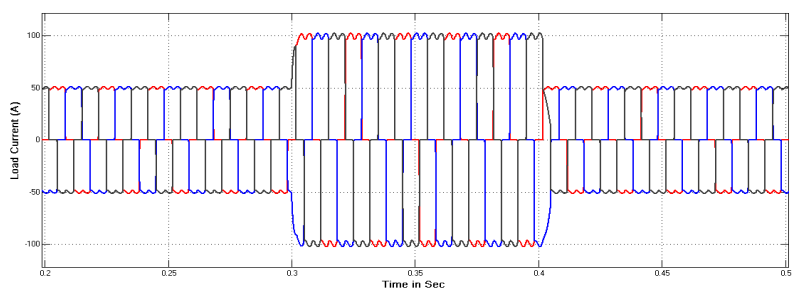

(d) . Load current

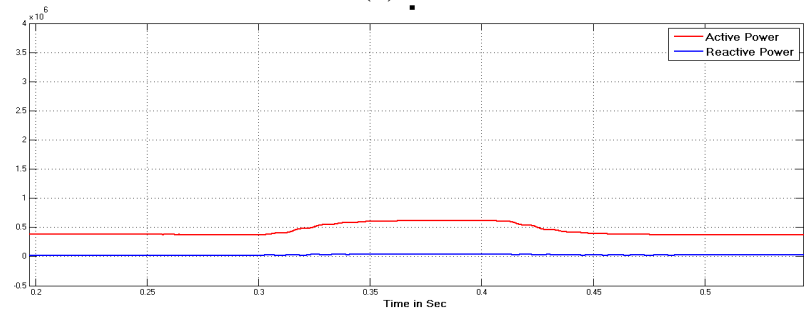

(e) Source Active and reactive powers

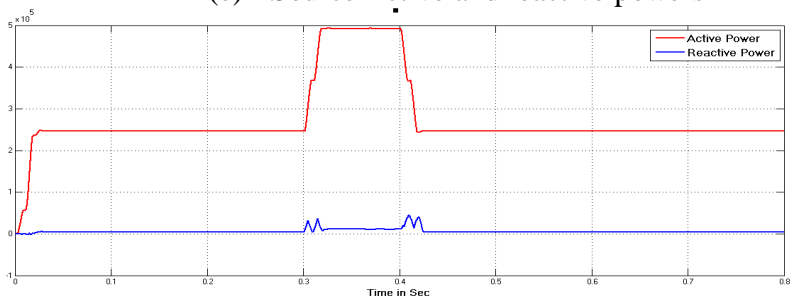

(f) Load active and reactive powers

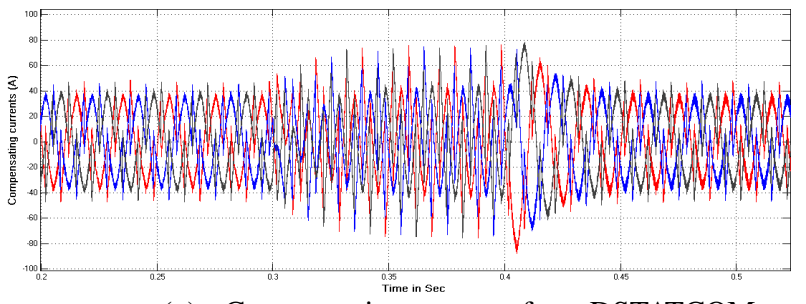

(g) Compensating currents from DSTATCOM

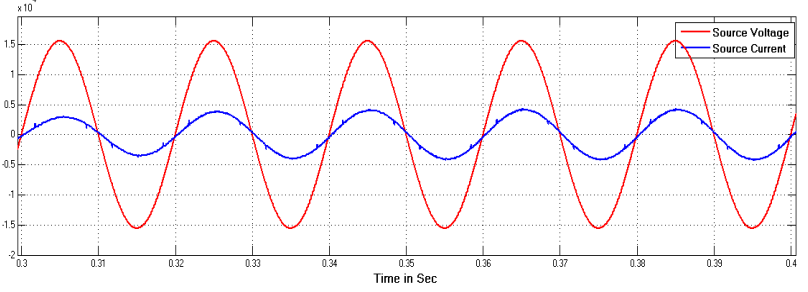

(h) source power factor

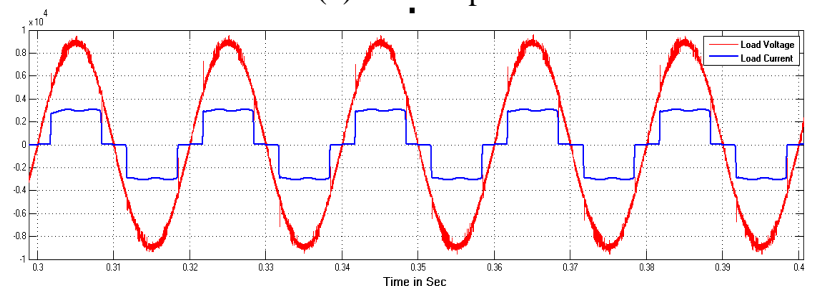

(i) Load power factor

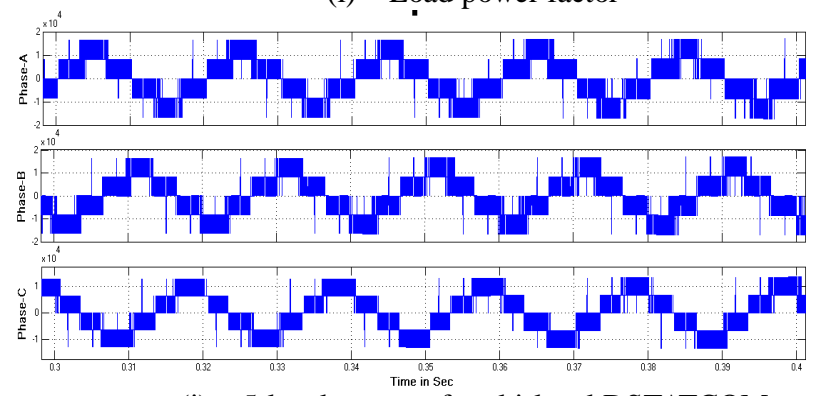

(j) 5-level output of multi-level DSTATCOM 


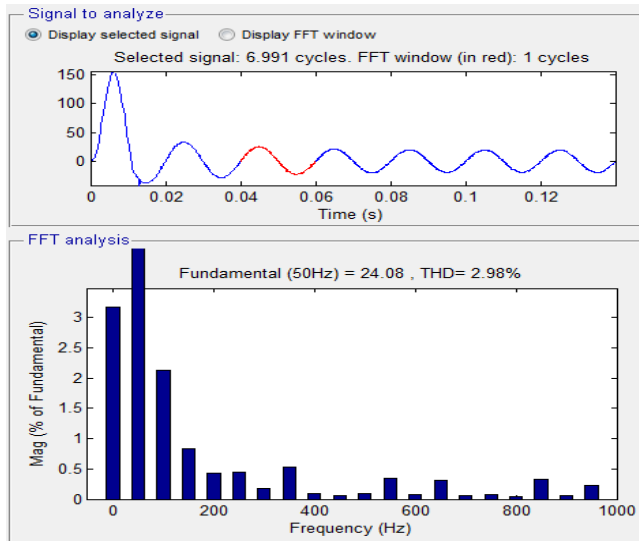

(k) THD in source current

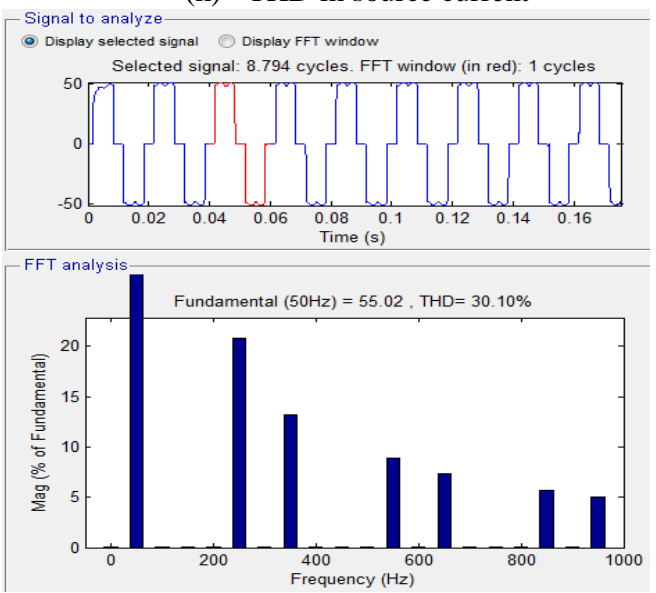

(1) THD in load current

Figure.7 Simulation Results of Balanced Non-Linear Load with Fuzzy-Logic Based IRP Controller

The simulation results of proposed 5-level CHB-MLI based DSTATCOM for PQ enhancement under non-linear balanced load by using traditional Fuzzy-IRP controller are clearly presented in Figure.7. In that, three-phase RMS $11 \mathrm{KV}$ is used as source voltage with a frequency of $50 \mathrm{~Hz}$. The source current is also maintained as sinusoidal because the 5-level CHB-MLI DSTATCOM topology is integrated at PCC of distribution system. Other than, the source current is always accordance with load current due to presence of non-linear loads. Suddenly the source current is increased with in a time period of $0.3 \mathrm{sec}$ to $0.4 \mathrm{sec}$ to achieve the load demand. The load voltage also maintained as sinusoidal and fundamental with a value of RMS $11 \mathrm{KV}$. Due to the non-linear load, the load current is highly harmonized components. The source side active power is also increased with respect to the increments in load while reactive power is maintained as zero. The 5-level CHB-MLI DSTATCOM injects the compensation current into PCC of distribution system to achieve three-phase distribution as balanced, sinusoidal, fundamental and linear nature by using in-phase compensation principle. Then the source current is in-phase with the voltage to represent the source side power-factor as unity. On other-hand, the load current is out of the phase with the load voltage to represent load side power-factor as non-unity condition. The 5-level CHB-MLI produces the stair-case voltage wave-shapes to represent the three-phase 5-level voltage. The harmonic profile of load current is $30.10 \%$ which is very high due to presence of balanced non-linear load and the source current is measured as $2.98 \%$ through FFT analysis, it is well within IEEE-519 standards. The THD value of source current under Fuzzy-IRP theory is very less over than traditional PI-IRP control theory which maximizes the over-all stability of the system.

4.3 Unbalanced Non-Linear load compensation with PI controller

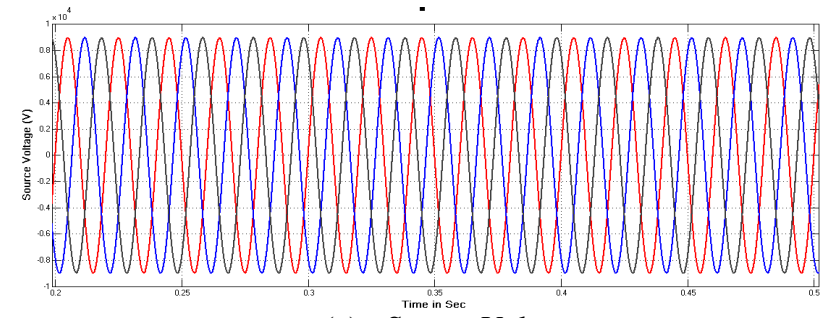

(a) Source Voltage

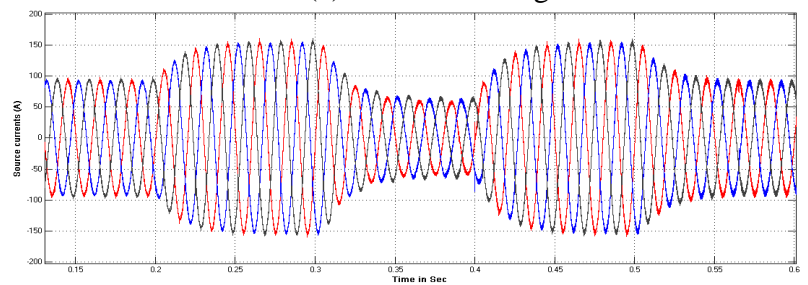

(b) Source current

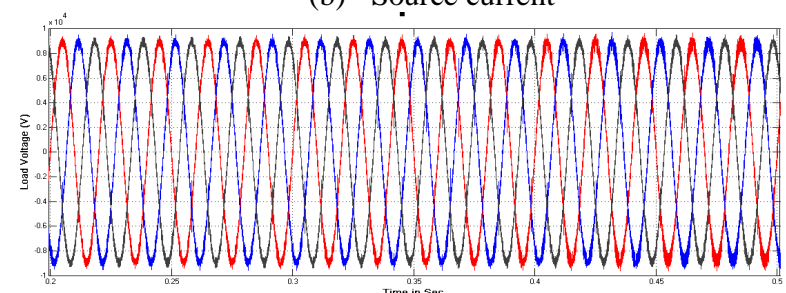

(c) Load voltage

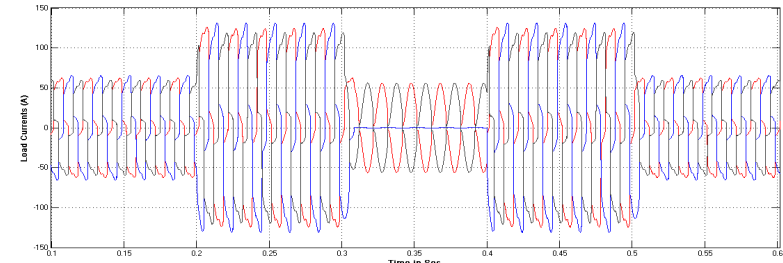

(d) Load current

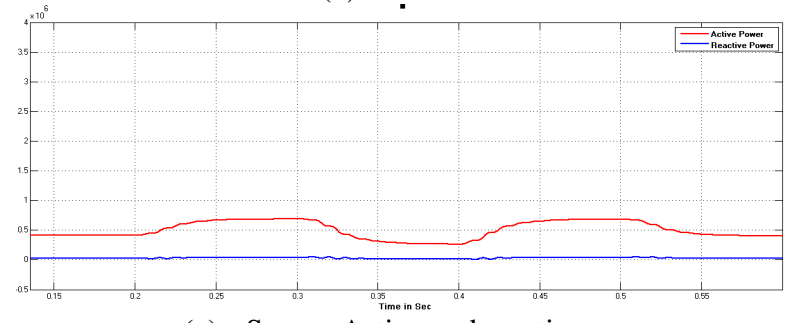

(e) Source Active and reactive powers

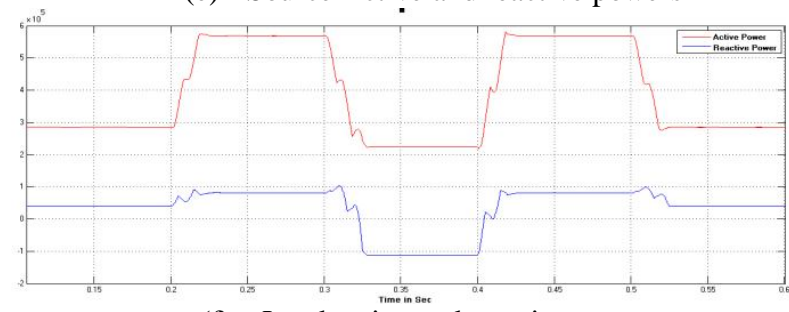

(f) Load active and reactive powers 


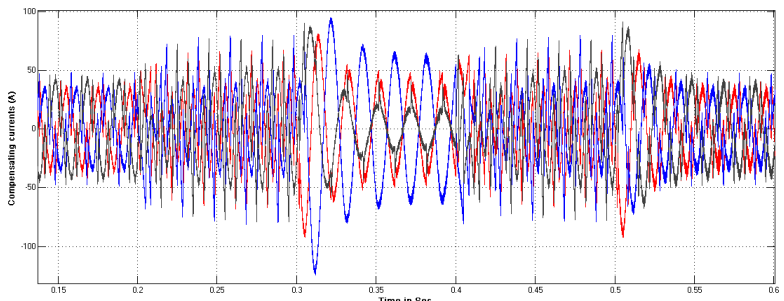

(g) Compensating currents from DSTATCOM

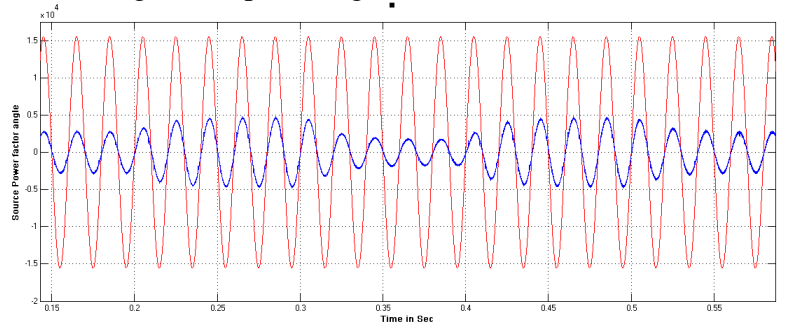

(h) source power factor

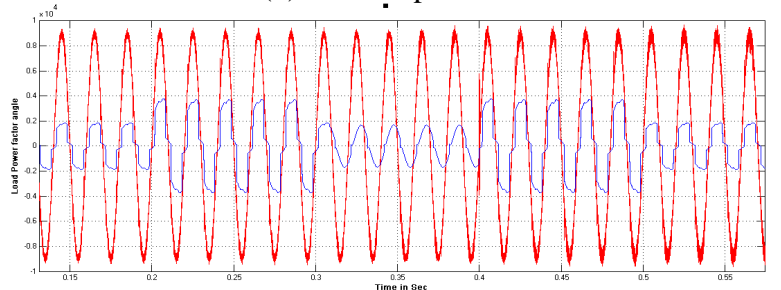

(i) Load power factor

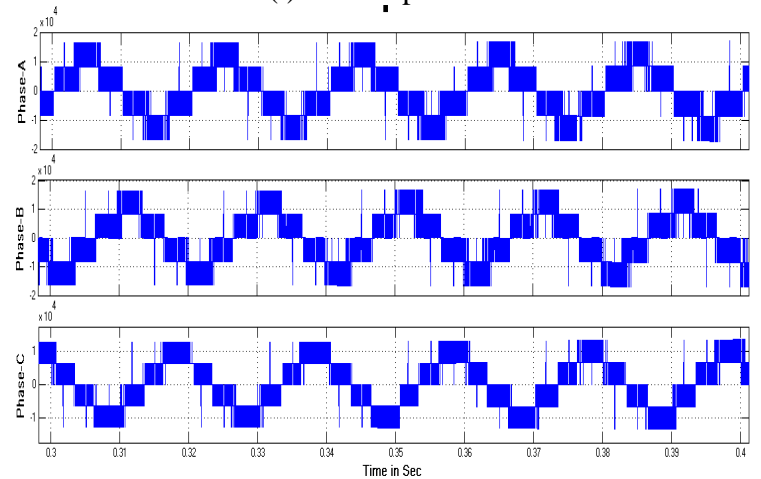

(j) 5-level output of multi-level DSTATCOM

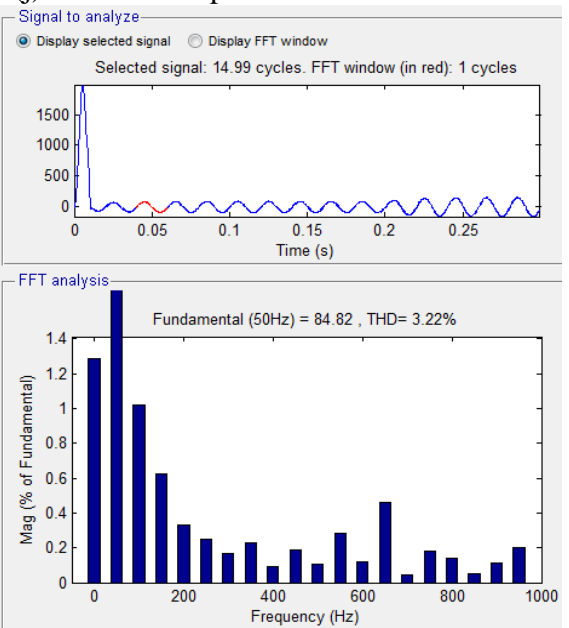

(k) THD in source current

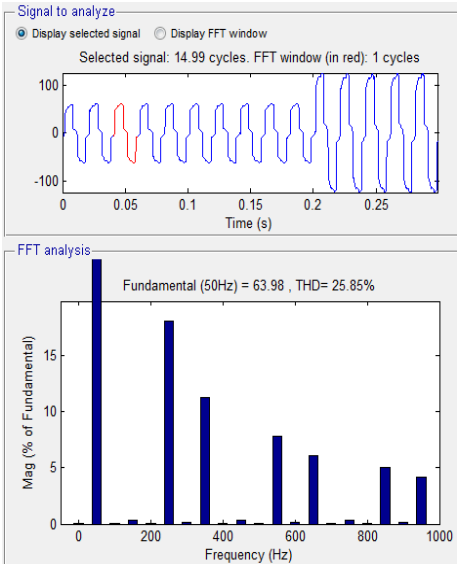

(1) THD in load current

Figure.8 Simulation Results of Un-Balanced Non-Linear Load with PI Based IRP Controller

The simulation results of proposed 5-level CHB-MLI based DSTATCOM for PQ enhancement under non-linear un-balanced load by using traditional PI-IRP controller are clearly presented in Figure.8. In that, three-phase RMS 11KV is used as source voltage with a frequency of $50 \mathrm{~Hz}$. The source current is also maintained as balanced and sinusoidal because the 5-level CHB-MLI DSTATCOM topology is integrated at PCC of distribution system. Other than, the source current is always accordance with load current due to presence of unbalanced non-linear loads. Suddenly the source current is increased with in a time period of $0.3 \mathrm{sec}$ to $0.4 \mathrm{sec}$ to achieve the load demand. The load voltage also maintained as sinusoidal and fundamental with a value of RMS $11 \mathrm{KV}$. Due to the un-balanced non-linear load, the load current is slightly unbalanced and harmonized components. The source side active power is also increased with respect to the increments in load while reactive power is maintained as zero. The 5-level CHB-MLI DSTATCOM injects the compensation current into PCC of distribution system to achieve three-phase distribution as balanced, sinusoidal, fundamental and linear nature by using in-phase compensation principle. Then the source current is in-phase with the voltage to represent the source side power-factor as unity. On other-hand, the load current is out of the phase with the load voltage to represent load side power-factor as non-unity condition. The 5-level CHB-MLI produces the stair-case voltage wave-shapes to represent the three-phase 5-level voltage. The harmonic profile of load current is $25.85 \%$ which is very high due to presence of un-balanced non-linear load and the source current is measured as $3.22 \%$ through FFT analysis, it is well within IEEE-519 standards.

4.4 Unbalanced Non-Linear load compensation with Fuzzy controller

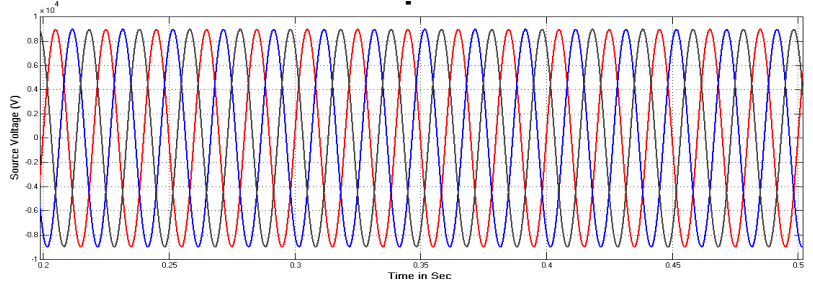

(a) Source Voltage 
J. Ganesh Prasad Reddy et al., International Journal of Emerging Trends in Engineering Research, 8(9), September 2020, 5135 - 5142

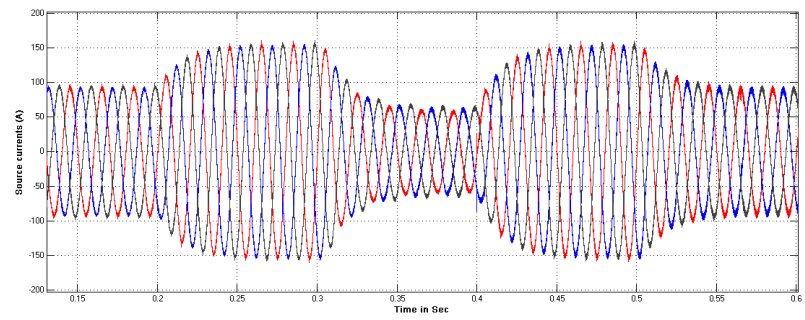

(b) Source current

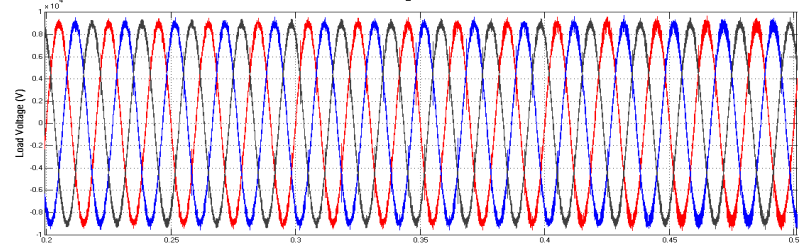

(c) Load voltage

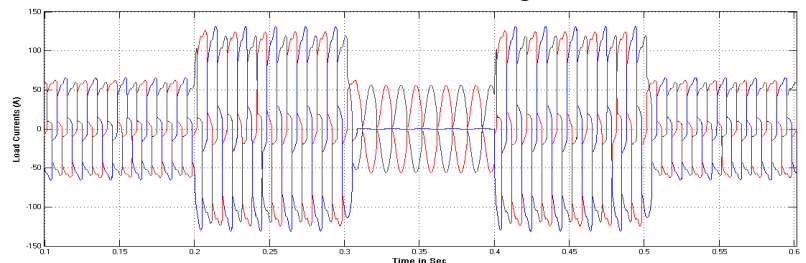

(d) Load current

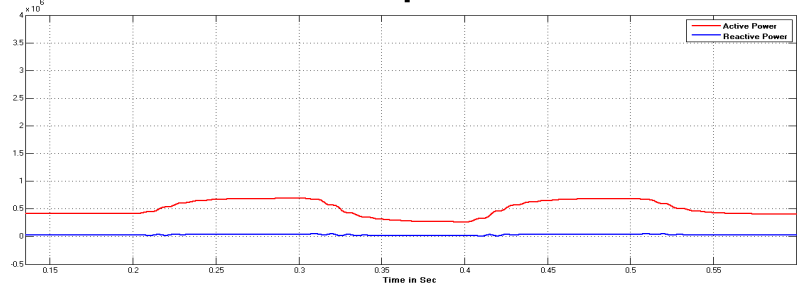

(e) Source Active and reactive powers

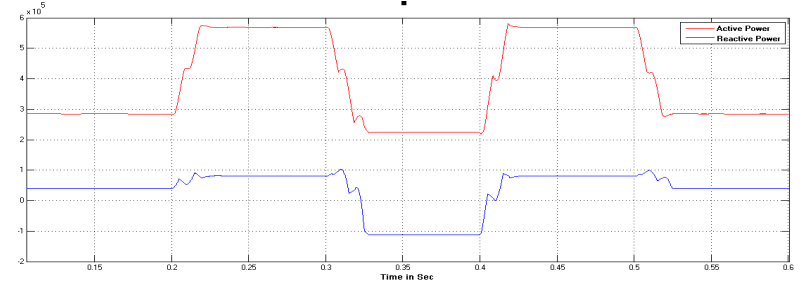

(f) Load active and reactive powers

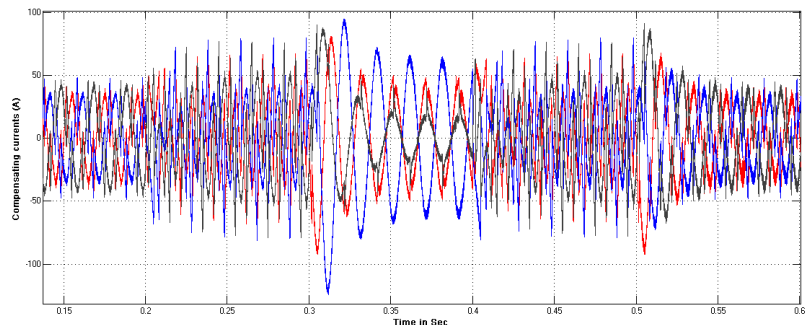

(g) Compensating currents from DSTATCOM

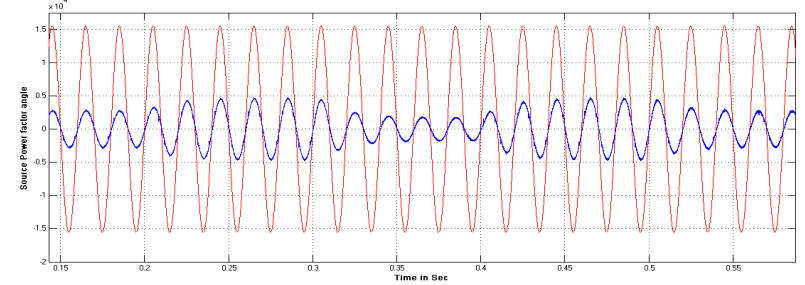

(h) source power factor

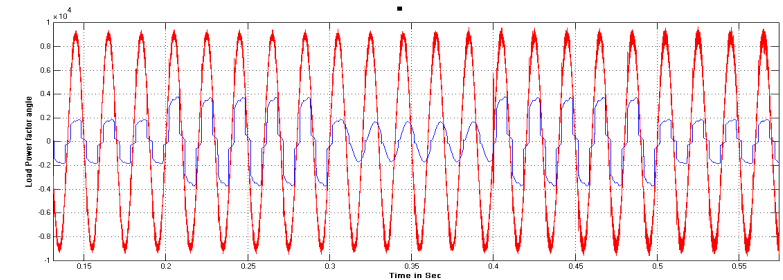

(i) Load power factor

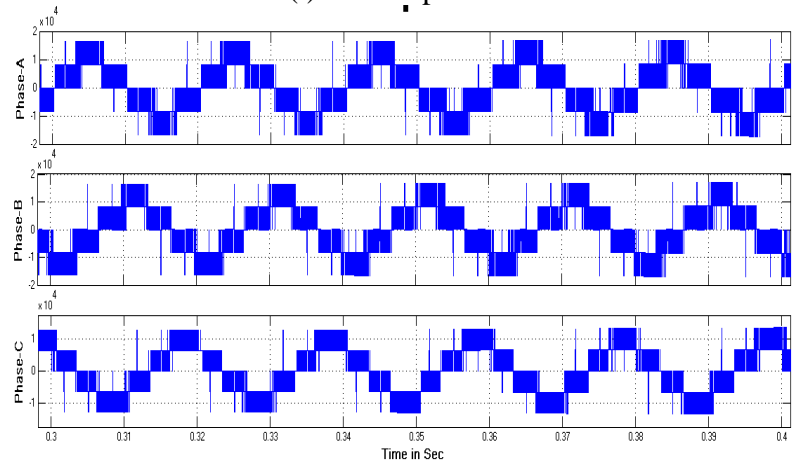

(j) 5-level output of multi-level DSTATCOM

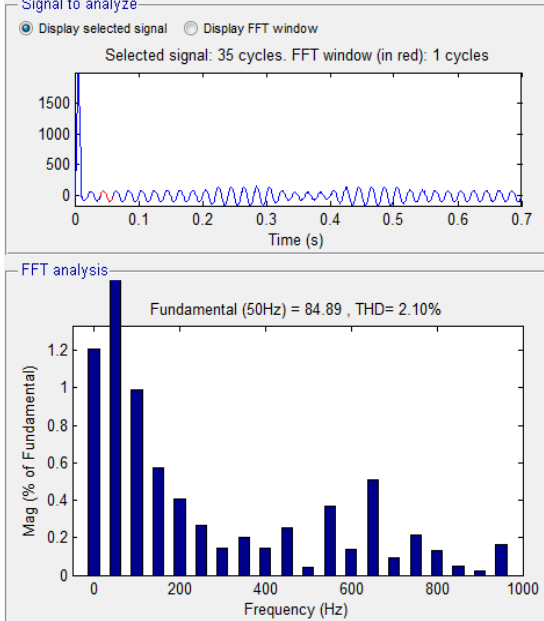

(k) THD in source current

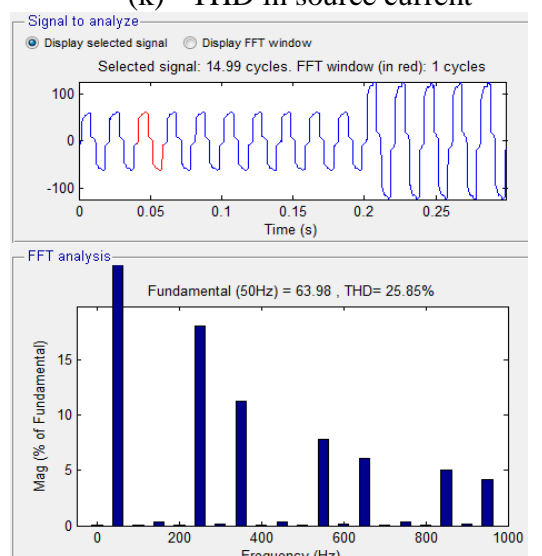

(l) THD in load current

Figure.9 Simulation Results of Un-Balanced Non-Linear Load with Fuzzy Based IRP Controller

The simulation results of proposed 5-level CHB-MLI based DSTATCOM for PQ enhancement under non-linear un-balanced load by using traditional Fuzzy-IRP controller are clearly presented in Figure.9. In that, three-phase RMS $11 \mathrm{KV}$ is used as source voltage with a frequency of $50 \mathrm{~Hz}$. The source current is also maintained as sinusoidal because the 
J. Ganesh Prasad Reddy et al., International Journal of Emerging Trends in Engineering Research, 8(9), September 2020, 5135 - 5142

5-level CHB-MLI DSTATCOM topology is integrated at PCC of distribution system. Other than, the source current is always accordance with load current due to presence of un-balanced non-linear loads. Suddenly the source current is increased with in a time period of $0.3 \mathrm{sec}$ to $0.4 \mathrm{sec}$ to achieve the load demand. The load voltage also maintained as sinusoidal and fundamental with a value of RMS $11 \mathrm{KV}$. Due to the un-balanced non-linear load, the load current is slightly unbalanced and harmonized components. The source side active power is also increased with respect to the increments in load while reactive power is maintained as zero. The 5-level CHB-MLI DSTATCOM injects the compensation current into PCC of distribution system to achieve three-phase distribution as balanced, sinusoidal, fundamental and linear nature by using in-phase compensation principle. Then the source current is in-phase with the voltage to represent the source side power-factor as unity. On other-hand, the load current is out of the phase with the load voltage to represent load side power-factor as non-unity condition. The 5-level CHB-MLI produces the stair-case voltage wave-shapes to represent the three-phase 5-level voltage. The harmonic profile of load current is $25.85 \%$ which is very high due to presence of un-balanced non-linear load and the source current is measured as $2.10 \%$ through FFT analysis, it is well within IEEE-519 standards. The THD value of source current under Fuzzy-IRP theory is very less over than traditional PI-IRP control theory which maximizes the over-all stability of the system. The harmonic analysis of traditional PI-IRP and Fuzzy-IRP controllers driven 5-level DSTATCOM under various load conditions is illustrated in Table.3. In that, the proposed Fuzzy-IRP driven 5-level DSTATCOM topology achieves good compensation features over the traditional PI-IRP control theory which maximizes the over-all system stability.

Table.3 Harmonic analysis with DSTATCOM in different working conditions

\begin{tabular}{|c|c|c|c|c|}
\hline \multirow{2}{*}{ THD } & \multicolumn{2}{|c|}{$\begin{array}{c}\text { Source Side } \\
\text { Current }\end{array}$} & \multicolumn{2}{c|}{ Load Side Current } \\
\cline { 2 - 5 } & $\begin{array}{c}\text { PI-IR } \\
\mathrm{P}\end{array}$ & $\begin{array}{c}\text { Fuzzy-IR } \\
\mathrm{P}\end{array}$ & $\begin{array}{c}\text { PI-IR } \\
\mathrm{P}\end{array}$ & $\begin{array}{c}\text { Fuzzy-IR } \\
\mathrm{P}\end{array}$ \\
\hline $\begin{array}{c}\text { Balanced } \\
\text { Non-Linea } \\
\text { r Load }\end{array}$ & $\begin{array}{c}3.83 \\
\%\end{array}$ & $2.98 \%$ & $\begin{array}{c}30.10 \\
\%\end{array}$ & $30.10 \%$ \\
\hline $\begin{array}{c}\text { Unbalance } \\
\mathrm{d}\end{array}$ & $\begin{array}{c}3.22 \\
\%\end{array}$ & $2.10 \%$ & $\begin{array}{c}25.85 \\
\%\end{array}$ & $25.85 \%$ \\
$\begin{array}{c}\text { Non-Linea } \\
\text { r Load }\end{array}$ & \begin{tabular}{c} 
\\
\hline
\end{tabular}
\end{tabular}

\section{CONCLUSION}

Elimination of harmonics for power quality enhancement is done with 5-level DSTATCOM is presented in this paper. PI and Fuzzy controlled DSTATCOM with multi-level structure are presented. Harmonic distortion in fuzzy controlled system smoothen the source current better than in PI case. Fuzzy controlled DSTATCOM gives better resistance to harmonic distortion and makes source current more nearer sinusoidal in shape compared to PI controlled DSTATCOM.

\section{REFERENCES}

1. H. Awad, M. H.J Bollen, "Power Electronics for Power Quality Improvements," IEEE Symposium on Industrial Electronics, vol.2, pp.1129- 1136, 2003.

2. A. Luo H. Xiao F. Ma et al. "Distribution static compensator based on an improved direct power control strategy" IET Power Electron. vol. 7 no. 4 pp. 957-964 2014.

3. T. S. Saggu, L. Singh and B. Gill, "Harmonics Mitigation in a Steel Industry Using 11-Level Cascaded Multilevel Inverter-Based DSTATCOM," in Canadian Journal of Electrical and Computer Engineering, vol. 40, no. 2, pp. 110-115, Spring 2017.

4. Juan W. Dixon, Gustavo Venegas and Luis A. Moran, "A Series Active Power Filter Based on a Sinusoidal Current-Controlled Voltage Source Inverter" IEEE Transactions on Industrial Electronics, Vol. 44, Issue: 5, Page(s): 612 - 620, Oct. 1997

5. G. Mallesham and C. S. Kumar, "Enhancement of power quality using UPQC for hybrid PEMFC and DFIG based wind energy system connected to weak grid," 2017 International Conference on Technological Advancements in Power and Energy ( TAP Energy), Kollam, India, 2017, pp. 1-6.

6. J. Ye, H. B. Gooi and F. Wu, "Optimal Design and Control Implementation of UPQC Based on Variable Phase Angle Control Method," in IEEE Transactions on Industrial Informatics, vol. 14, no. 7, pp. 3109-3123, July 2018

7. M. Pradhan and M. K. Mishra, "Dual P-Q Theory based Energy Optimized Dynamic Voltage Restorer for Power Quality Improvement in Distribution System," in IEEE Transactions on Industrial Electronics, 2018 (early access).

8. Yash Pal, A. Swarup, Bhim Singh, "A control strategy based on UTT and of three-phase, four-wire UPQC for power quality improvement" International Journal of Engineering, Science and Technology Vol. 3, No. 1, 2011, pp. 30-40.

9. H. Akagi, Y. Kanazawa, A. Nabae, "Generalized Theory of the Instantaneous Reactive Power in Three Phase Circuits", in Proc. IPECTokyo'83 Int. Conf. Power Electronics, Tokyo, pp. 1375-1386

10. Mohammad Al Saaideh1, Ola Ananbeh, Tamadher Almomani, Eyad A. Feilat, Hussam J. Khasawneh, "Power Quality Audit of a School of Engineering Building - Case Study", International Journal of Emerging Trends in Engineering Research, Vol.8, No.1, 2020, pp.151-156.

11.Jahnavi, Koganti Srilakshmi, P. Ravi Babu, P. Aravindhababu, "Unified Power Quality Conditioner for Power Quality Enhancement of Distribution System Using Space Vector Pulse Width Modulation Based Fuzzy Controller", International Journal of Emerging Trends in Engineering Research, Vol.8, No.6, 2020, pp.2852-2860. 